\title{
Extra-Hepatic Hepatoid Carcinomas in Female Reproductive System: Three Case-Reports with a Literature Review
}

This article was published in the following Dove Press journal: Cancer Management and Research

\author{
Yao Liu (iD) ${ }^{1,2}$ \\ Ruiqi Zhou',2 \\ Shourong Wang ${ }^{1,2}$ \\ Guiyu Zhang ${ }^{1,2}$ \\ 'Department of Gynecology, Qilu \\ Hospital of Shandong University, Jinan, \\ Shandong Province, People's Republic of \\ China; ${ }^{2}$ Qilu Hospital, Cheeloo College \\ of Medicine, Shandong University, Jinan, \\ Shandong Province, People's Republic of \\ China
}

Purpose: Hepatoid carcinoma of the ovary (HCO) and hepatoid carcinoma of the uterus (HCU) are rare malignancies that can be difficult to distinguish from other diseases such as hepatocellular carcinoma. In extremely rare cases, patients are negative for $\alpha$-fetoprotein (AFP) by immunohistochemistry. Here we report 3 cases of $\mathrm{HC}$ of the female reproductive system, including 1 that was negative for AFP.

Patients and Methods: Three women aged 48, 56, and 67 years were treated at Qilu Hospital of Shandong University for HCO or HCU. We describe these cases in detail, including clinical features, diagnosis, treatment, and outcome, and review similar cases reported in the literature. Results: All of our patients underwent surgery including hysterectomy and bilateral adnexectomy, and were treated with platinum-based chemotherapy. One patient died 3 months after the operation, and the other 2 are alive 22 and 63 months post surgery.

Conclusion: The first-choice treatment for HCO and HCU is staging surgery, which should be followed by platinum-based chemotherapy.

Keywords: HCO, HCU, therapy, prognosis

\section{Introduction}

Extrahepatic hepatoid carcinomas (HCs) are a rare group of aggressive tumors with clinical and pathologic features similar to hepatocellular carcinoma (HCC). Ishikura and Scully first proposed the concept of a "hepatoid carcinoma" in 1987 when they described a case involving the ovary that was immunopositive for $\alpha$-fetoprotein (AFP). ${ }^{1}$ Positive staining for AFP by immunohistochemistry was considered to be an essential feature of this tumor. ${ }^{2}$ Another case of AFP-producing endometrial adenocarcinoma was reported in 1988. These tumors can arise in many tissues outside the liver (most commonly in the stomach) but rarely occur in the female reproductive system. ${ }^{3-5}$ Here we report 3 such cases that were treated at Qilu Hospital of Shandong University. The patients were aged 48, 56, and 67 years; 2 had hepatoid carcinoma of the ovary (HCO), with negative staining for AFP in 1 case; and the third patient had hepatoid carcinoma of the uterus (HCU).

\section{Case Report Case I (AFP Immunonegativity)}

A 66-year-old postmenopausal female (G2P2L2) was admitted to our hospital with abdominal pain and distension that had persisted for 20 days and emesis that had
Qilu Hospital of Shandong University, Wenhuaxi Road 107, Jinan, Shandong

Province, People's Republic of China

Tel +86 I856008I737

Email zgy5566@sdu.edu.cn

Cancer Management and Research 2021:13 1625-1636 
lasted for 7 days. The patient had a history of bilateral tubal ligation but no family history of gynecologic cancer, hepatitis, or any other hepatopathy, and was negative for hepatitis B surface antigen (HBsAg) at admission. Physical examination revealed a giant $(10 \times 15 \mathrm{~cm})$ irregular lump in her abdominopelvic cavity but no hepatosplenomegaly or lymphadenopathy. Her cervix uteri was atrophic and the uterus was undetectable to the touch. The shifting dullness test yielded a positive result.

A heterogeneous hypoechoic solid tumor measuring $13 \times 12 \times 8.1 \mathrm{~cm}$ with unclear margin was observed in the bottom left area of the abdominal cavity by color Doppler ultrasound. The tumor contained a few liquid dark areas and streaked bloodstream signals. The uterus was contracted to $4.3 \times 3.9 \times 2.8 \mathrm{~cm}$. A sonolucent area of fluid was observed in the abdominal cavity at a depth of $7.1 \mathrm{~cm}$, which increased to about $11 \mathrm{~cm}$ after 15 days. An enhanced computed tomography (CT) scan of the abdomen and pelvis revealed multiple masses with heterogeneous density, with the largest measuring $13.8 \mathrm{~cm}$ in diameter. The omentum and peritoneum were thickened, but the liver and lymph nodes showed no abnormalities (Figure 1A). Levels of tumor markers were as follows: cancer antigen $(\mathrm{CA}) 125,795.40 \mathrm{U} / \mathrm{mL}$ (normal: <35 U/ $\mathrm{mL}$ ); CA153, 735.52 U/mL (normal: <25 U/mL); CA199, $162.80 \mathrm{U} / \mathrm{mL}$ (normal: <39 U/mL); and cytokeratin 19 fragment (CYFRA21-1), $18.54 \mathrm{ng} / \mathrm{mL}$ (normal $<3.3 \mathrm{ng}$ / $\mathrm{mL})$. Serum AFP level was $2.05 \mathrm{ng} / \mathrm{mL}$, which was within the normal range $(<20 \mathrm{ng} / \mathrm{mL})$.

The patient was diagnosed with a malignant ovarian tumor and underwent hysterectomy as well as dissection of bilateral adnexa, greater omentum, and metastatic nodules on the mesentery and in the pelvic cavity. About $2 \mathrm{~L}$ of pale bloody ascites was removed. Bilateral ovaries were slightly enlarged with cauliflower-like neoplasms on the surface. The right oviduct was thickened but the left oviduct was normal. An enormous cystic solid tumor measuring $15 \times 10 \times 9 \mathrm{~cm}$ was found beside the colon sigmoideum that was tightly adhered to the mesentery and had an $8-\mathrm{cm}$ long crevice. A cauliflower-like neoplasm approximately $8 \times 7 \mathrm{~cm}$ in size was observed near the splenic flexure of the colon, but excision was not attempted because of its tight adhesion to the spleen and transverse colon. Numerous tumor nodules were present on the omentum majus, with the largest one approximately $5 \times 6 \mathrm{~cm}$ in diameter in the omental bursa. Friable cauliflower-like neoplasms of variable size were observed on the peritoneum and mesentery. The gall bladder was enlarged to about $5 \times 5 \mathrm{~cm}$ and the vermiform appendix was tortuous and thickened. No abnormalities were observed in the liver. Histopathologic analysis of frozen sections strongly suggested the possibility of sex cord stromal tumors. The final diagnosis was stage IIIC HCO.

The patient completed 1 cycle of carboplatin $(450 \mathrm{mg})$ and docetaxel $(90 \mathrm{mg}$ ) but refused additional cycles of chemotherapy because of serious side effects. The patient died 3 months after her surgery. The pathologic findings are shown in Figure 2 and supplementary Figure 1.

\section{Case 2}

A 48-year-old postmenopausal female (G5P2A3L2) was admitted to our hospital with a left lower abdominal mass with tenderness that had persisted for 5 days. The patient had a history of Budd-Chiari syndrome and no family history of gynecologic tumors. She had no history of hepatitis or any other hepatopathy, and was negative for HBsAg at admission. Physical examination revealed a hard $8 \times 9 \times 10 \mathrm{~cm}$ mass in the left adnexa area along with tenderness. No abnormality was found in the right adnexa or uterus.

Ultrasonography showed a $10.3 \times 8.6 \mathrm{~cm}$ solid mass in the left adnexa area. High blood flow signals were observed and the depth of the sonolucent area of fluid in the abdominal cavity was about $4.0 \mathrm{~cm}$. There was no significant abnormality in the liver. The enhanced CT scan revealed a lesion in the subcapsular area of the right lobe of the liver that was highly suggestive of a metastatic tumor (Figure 1B). Enhanced magnetic resonance imaging (MRI) showed circular T1 and T2 signals and an annular high diffusion-weighted imaging (DWI) signal in the subcapsular area of the right lobe of the liver, with uneven annular enhancement and a diameter of about $2.2 \mathrm{~cm}$ that supported the possibility of a metastatic tumor (Figure 1C). Portal hypertension and cholecystitis were observed. In the left adnexa area, there was a round cystic mass about $9.5 \times 8.8 \mathrm{~cm}$ in size with uneven density, unclear boundary, and uneven slight enhancement (Figure 1D). The tumor was considered as originating in the ovary. The density of fat space in the peritoneal cavity around the tumor was increased, and the boundary between the colon and surroundings was unclear. There were no enlarged lymph nodes in the pelvic cavity. Serum levels of biochemical markers were as follows: CA125, $81.95 \mathrm{U} / \mathrm{mL}$ (normal: <35 U/mL); CA724, $8.73 \mathrm{U} / \mathrm{mL}$ (normal: $<6.9 \mathrm{U} / \mathrm{mL}$ ); and anti-Müllerian hormone, 0.01 $\mathrm{U} / \mathrm{mL}$ (normal: $0.05-2.06 \mathrm{ng} / \mathrm{mL}$ ). Serum AFP was extremely elevated at $>24,200.00 \mathrm{ng} / \mathrm{mL}$, which decreased to $3334.00 \mathrm{ng} / \mathrm{mL} 12$ days after the surgery. 

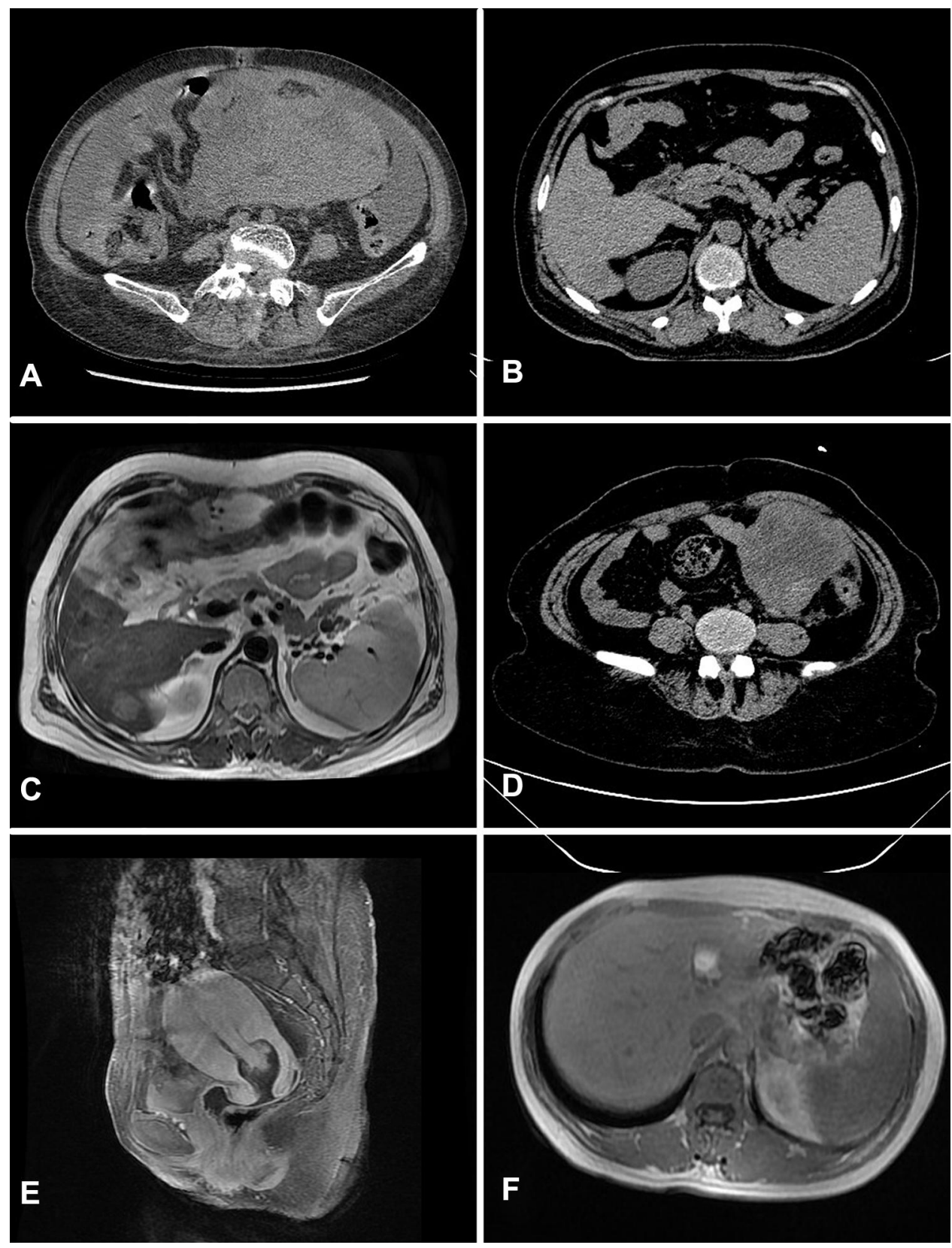

Figure I CT and MR images of cases: (A) for CT image of case I; (B) for CT image of case 2; (C) for MR image of case 2; (D) for CT image of case 2; (E) for MR image of case 3; (F) for MR image of case 3.

The patient underwent exploratory laparotomy. There was cystic enlargement of the left ovary, which was about $8 \times 8 \times 6 \mathrm{~cm}$ with an incomplete capsule and anabrotic surface. No obvious abnormalities were found in the appearance of the right adnexa and uterus, and there were no visible tumors or other abnormalities in the liver and intestines.

Frozen sections from the left adnexectomy showed poorly differentiated adenocarcinoma. The patient underwent extrafascial hysterectomy, bilateral bilateral adnexectomy, greater omentum resection, pelvic lymph node dissection, para-aortic lymph node sampling, and appendectomy.

The final pathologic diagnosis was stage IC2 HCO. Tumor cells were large and polygonal with cytoplasm ranging from pink and granular to clear. Nuclei are round to oval with distinct nucleoli. The cells resembled those of HCC. Immunostaining results were as follows: $\mathrm{AFP}(+)$, arginase (Arg)-1(+), glypican (GP)3(+), hepatocyte paraffin $1(+)$, cytokeratin $(\mathrm{CK}) 8 / 18(+)$, Sal-like protein (SALL)4(-), cluster of differentiation (CD)117(-), CD30 




Figure 2 Pathological findings for case I: (A) (H\&Ex 100), (B) (H\&E×200), Microscopically, tumor cells are large and polygonal, with abundant and eosinophilic cytoplasm. The nuclei were lightly stained and appeared round or ovoid, some cells were binucleated, the nucleoli were obvious, mild atypia, and mitotic figures were seen. The nuclei are lightly stained, round or ovoid, with obvious nucleoli, and some of the cells are binucleate. Slight atypia and mitotic figures are visible. The tumor has an infiltrative growth and is poorly demarcated from normal tissue. (C) negative stain for AFP $(\times 100)$. (D) partial positive stain for Hepatocyte-paraffin I( $\times 100)$. Besides, we got immunohistochemical analysis as follows: PAX8(-), P53(-), PI6(-), ER(-), PR(-).

$(-), \quad \mathrm{AFP}(+), \quad \alpha-i n h i b i n(-), \quad \mathrm{CK}( \pm), \quad \mathrm{CK} 7(-)$, octamerbinding protein (OCT)4(-), chromogranin $(\mathrm{Cg}) \mathrm{A}(-)$, synaptophysin $(\mathrm{Syn})(-)$, paired-box $(\mathrm{PAX}) 8(-)$, estrogen receptor $(\mathrm{ER})(-)$, progesterone receptor $(\mathrm{PR})(-)$, Wilms' tumor $(\mathrm{WT})(-)$, and $\mathrm{Ki} 67(40 \%+)$.

The patient completed 6 cycles of intravenous chemotherapy with paclitaxel liposome $(270 \mathrm{mg})$ plus carboplatin $(600 \mathrm{mg})$. Serum AFP level decreased to $127.00 \mathrm{ng} /$ $\mathrm{mL}$ after the first cycle and was normal after the second cycle. The enhanced CT scan showed a small liveroccupying lesion and enlarged retroperitoneal lymph nodes 4 months after the operation. After consulting with the surgeon, the lesion was determined to be metastatic disease. The patient underwent radiofrequency ablation of the lesion and is alive over 22 months later. At the most recent physical re-examination, no obvious abnormality was found in her pelvic cavity. The pathologic findings are shown in Figure 3 and supplementary Figure 2.

\section{Case 3}

A 48-year-old premenopausal female (G3P2A1L2) was admitted with menostaxis and menorrhagia. The patient had a history of bilateral tubal ligation and no family history of gynecologic malignancies. She had no history of hepatitis or any other hepatopathy and was negative for HBsAg at admission. Physical examination revealed a tumor in the external cervix about $4.5 \mathrm{~cm}$ in diameter with an ulcerated surface that bled on contact. Her uterus size was equivalent to about 2 months of pregnancy, with regular shape, good movement, and mild tenderness. Ultrasonography showed that the size of the uterus was increased to $11.0 \times 7.5 \times 6.2 \mathrm{~cm}$, with a regular shape and a $2.9 \times 2.6-\mathrm{cm}$ low-echo area whose pedicle was connected to the uterine cavity. The liquid dark area in the abdominal cavity had a depth of $7.1 \mathrm{~cm}$ that increased to about $11 \mathrm{~cm}$ after 15 days. An enhanced MRI scan of the pelvis and abdomen revealed an irregular mass in the uterine cavity near the uterine isthmus with a clear boundary and a size of about $3 \times 2.5 \times 2.6 \mathrm{~cm}$, showing a high DWI signal with the same degree of enhancement as the myometrium (Figure 1E). No abnormal signals were found in bilateral adnexa and rectum, and multiple small lymph nodes $<1 \mathrm{~cm}$ in diameter were present in the pelvic cavity. The signal of the liver parenchyma was nonhomogeneous (suggesting fibrosis), and no abnormal enhancement was observed in any phase of the enhanced scan (Figure 1F). There were 


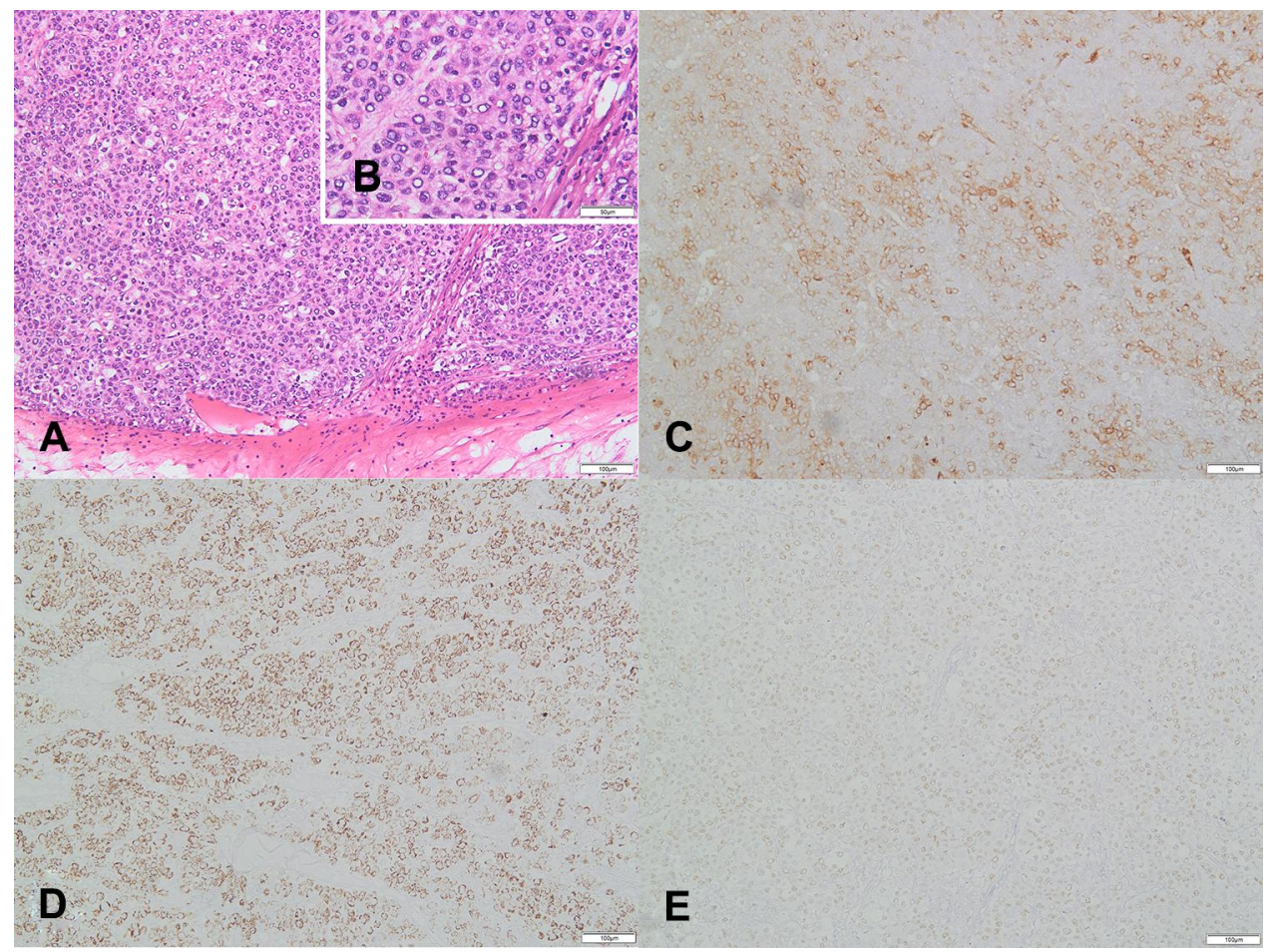

Figure 3 Pathological findings for case 2: (A) (H\&Ex 100), (B) (H\&E×200),Microscopically, tumor cells are large and polygonal, with abundant and eosinophilic cytoplasm. The nuclei lightly stained are round, elliptic or irregular in shape, with inconspicuous nucleoli. Some of the nuclei are vacuolated with chromatin squeezed under the thickened nuclear membrane. The nuclei are highly heteromorphic, with active mitoses and some of the cells are binuclear or multinucleate. The tumor has an infiltrative growth and is poorly demarcated from normal tissue. (C) positive stain for AFP $(\times 100)$. (D) positive stain for Hepatocyte-paraffin I( $\times 100)$. (E) negative stain for SALL-4 $(\times 100)$. Besides, we got immunohistochemical analysis as follows: PAX8(-), P53(-), PI6(-), ER(-), PR(-).

no abnormalities in the intra- and extrahepatic bile ducts or gallbladder and no obvious enlargement of lymph nodes in the abdominal cavity and retroperitoneum. Serum levels of carcinoembryonic antigen (CEA), CA-125, CA-153, CA-199, CA-724, and a CYFRA21-1 were within normal ranges. Two months before admission, the patient's serum AFP level was $1210 \mathrm{ng} / \mathrm{mL}$ (normal: $<20 \mathrm{ng} / \mathrm{mL}$ ), and the maximum level before surgery was $8191 \mathrm{U} / 1$.

The patient had been treated by curettage at a local hospital, and pathologic analysis of the biopsy indicated a malignant tumor. Pathologic findings from another hospital suggested the possibility of metastatic HCC, while primary hepatoid yolk sac tumor (HYST) could not be excluded. A tentative diagnosis of placental site trophoblastic tumor with focal infiltration of muscle tissue was made after 1 week based on the following immunohistochemistry results: $\mathrm{CK}(+), \mathrm{AFP}(+)$,human chorionic gonadotropin $(\mathrm{hCG})(-)$, human placental lactogen $(\mathrm{hPL})(-)$, smooth muscle actin (SMA) $(-), \alpha$-inhibin $(-)$, hepatocyte paraffin 1 (-), and GP3(-). Clinical examination was necessary in order to exclude liver cancer metastasis. Histopathologic examination at our hospital revealed epithelioid cells with abundant cytoplasm in the endometrial tissues, and hepatoid adenocarcinoma was considered based on immunohistochemical analysis at our hospital, which yielded the following results: $\mathrm{CK}(+)$, $\operatorname{AFP}(+)$, epithelial membrane antigen $(\mathrm{EMA})(+)$, vimentin $(-)$, OCT $-4(-), \alpha 1$ antitrypsin $( \pm)$, hepatocyte paraffin 1(-), and $\operatorname{GPC} 3(-)$.

The patient was diagnosed with endometrial cancer and underwent modified radical hysterectomy, bilateral adnexectomy, pelvic lymph node dissection, and anterior sacral lymph node resection. Bilateral adnexa appeared normal, and there were several enlarged lymph nodes in the pelvic cavity. By dissecting the uterus, a dark purple neoplasm about $4 \times 3 \times 3 \mathrm{~cm}$ in size was found in the upper part of the uterine cavity near the fundus that had invaded the superficial muscle layer and caused local necrosis, with no obvious abnormalities in the cervix. Frozen sections showed localized endometrial carcinoma infiltrating into the superficial muscle layer. The final pathologic diagnosis was stage IA HCU.

The patient's serum AFP level gradually decreased to $4212 \mathrm{ng} / \mathrm{mL}$ on the second day after the operation and to $680.6 \mathrm{ng} / \mathrm{mL} 7$ days later. She received 6 cycles of intravenous chemotherapy with taxol $(240 \mathrm{mg})$ and carboplatin (600 mg). After the first cycle, serum AFP decreased and 
after the second cycle, the level was below the normal range. There were no abnormalities in serum AFP level or by liver imaging during follow-up, and the patient remains alive over 63 months later. Pathologic findings are shown in Figure 4 and supplementary Figure 3.

\section{Discussion}

Ovarian cancer is one of the most common gynecological malignancies, accounting for $2.5 \%$ of all female cancers and $21 \%$ of malignancies of the female genital tract. It is often diagnosed in the late stages and has poor prognosis, with a low cure rate $(<40 \%)$ and accounting for $5 \%$ of total cancer deaths in women in the United States. ${ }^{6}$ Five subtypes of ovarian carcinoma that together account for over $95 \%$ of cases have been distinguished based on histopathologic, immunohistochemical, and molecular genetic featuresnamely, high-grade serous (70\%), endometrioid (10\%), clear cell $(10 \%)$, mucinous $(3 \%)$, and low-grade serous $(<5 \%)$ carcinoma. ${ }^{7}$ Primary HCO is a rare, aggressive tumor that shares clinical and pathologic features with HCC and is thought to have 2 histogenic origins - ie, superficial epithelium and germ cells, although neither of these are supported by conclusive evidence. ${ }^{8}$ This tumor type was labeled as HC because it lacked an adenocarcinomatous component, ${ }^{1}$ until the possibility of a surface epithelial origin was suggested. ${ }^{9,10}$

Only 39 cases of HCO have been reported to date; most patients have been postmenopausal females ranging in age from 27 to 78 years, with a median age of 55 years. Most cases were diagnosed at a late clinical stage and presented with abdominal distension and lower abdominal pain with rapid progression of the disease. Primary HCU is also rare, with only 11 cases reported in the literature. Most patients were postmenopausal women except for our 48-year-old patient, with an average age of 64 years. The adenocarcinomatous component coexisted in all cases, and sarcomatous components were observed in 2 cases. HCU has very poor prognosis, with the majority of patients experiencing tumor recurrence or death within 12 months of diagnosis (Tables 1 and 2).

Most HCO patients have a higher-than-normal serum AFP level, with only 3 recorded cases of normal AFP levels. CA-125 levels were also higher than normal in most patients. CT and ultrasound imaging showed a unilateral (occasionally bilateral) mass that was generally solid or accompanied by partial cystic components. Both of our HCO patients had solid pelvic masses that

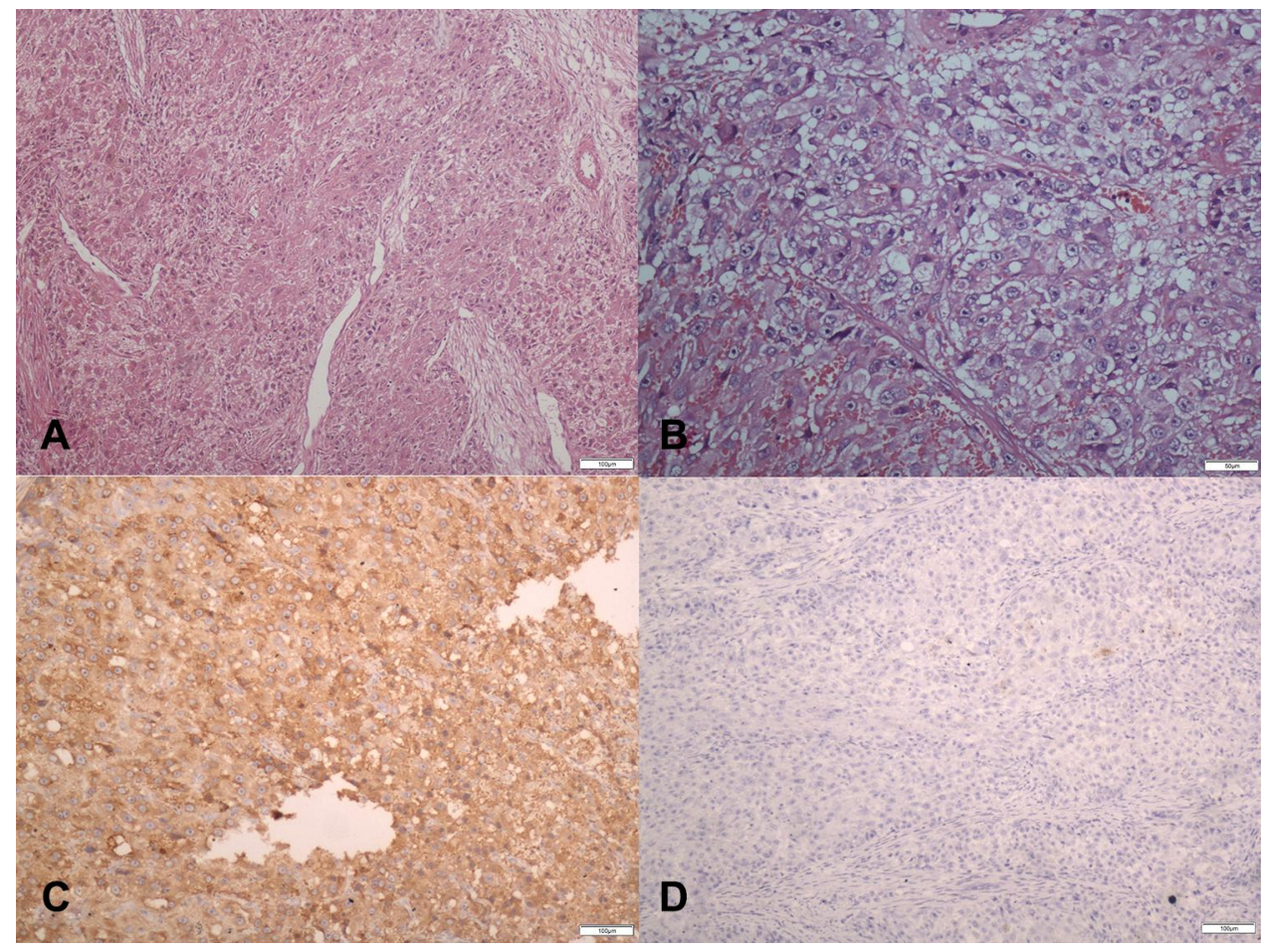

Figure 4 Pathological findings for case 3: (A) (H\&Ex|00), (B) (H\&E×200),Microscopically, tumor cells are large and polygonal, with abundant and eosinophilic cytoplasm. The nuclei were round or oval in shape, varied in size, and some cells were binucleate. The nuclear membrane was thickened, the nucleus was pale stained, the nucleolus was obvious, atypia was not obvious, and mitotic figures were seen. The tumor tissue is poorly defined from normal tissue and shows infiltrative growth. (C) positive stain for AFP(×100). (D) negative stain for Hepatocyte-paraffin I(×100). Besides, we got immunohistochemical analysis as follows: PAX8(-), P53(-), PI6(-), ER(-), PR(-). 
Table I Clinical Features, Treatment, and Outcomes of HCO

\begin{tabular}{|c|c|c|c|c|c|c|c|c|}
\hline Case & Age & Site/Size (cm) & Stage & AFP & CAI 25 & Post-Operative Treatment & Outcome & Reference \\
\hline I & 42 & L 6.4; R 5.4 & IIB & NA & NA & Chemoradiation & Dead (5 years) & {$[\mathrm{I}]$} \\
\hline 2 & 71 & L 20 & IIIC & NA & NA & Radiation & Alive (2 years) & {$[\mathrm{I}]$} \\
\hline 3 & 57 & R $10.5 \times 7.5 \times 5.5$ & IIIC & NA & NA & NA & Dead (4 months) & {$[1]$} \\
\hline 4 & 78 & NA & IIIC & $\begin{array}{c}2420 \\
\text { (postop) }\end{array}$ & NA & Melphalan & Dead (8 months) & {$[1]$} \\
\hline 5 & 68 & R $10 \times 6 \times 5$ & III & NA & NA & Chemoradiation & Dead (10 months) & {$[1]$} \\
\hline 6 & 43 & $\begin{array}{l}\mathrm{L} 6 \times 7 \times 7 ; \mathrm{R} 6 \times \\
6 \times 8\end{array}$ & IIIC & 74 & 158 & Cisplatin/epirubicin/ifosfamide & Alive (2 years) & [2] \\
\hline 7 & 42 & R $17 \times 6$ & IA & 600 & NA & Carboplatin/paclitaxel & Dead (16 months) & [5] \\
\hline 8 & 64 & $R 18 \times 17 \times 16$ & IA & 23,170 & 58 & IP cisplatin; chemotherapy & Alive (2 years) & [9] \\
\hline 9 & 72 & L 9.5; R 5.4 & III & NA & 802 & Carboplatin & Recurred (6 months) & {$[10]$} \\
\hline 10 & 69 & L 12 & IA & 590 & 11 & Patient declined & NA & {$[\mathrm{II}]$} \\
\hline 11 & 53 & L 10 & IIB & 257,522 & Normal & Carboplatin/paclitaxel & Alive (13 months) & {$[\mathrm{II}]$} \\
\hline 12 & 76 & L 16 & IIB & 24,000 & NA & None & Alive (4 years) & {$[\mathrm{II}]$} \\
\hline 13 & 46 & L 4.5; R 6.5 & III & b30,000 & 414 & $\begin{array}{l}\text { Carboplatin/paclitaxel; } \\
\text { sorafenib }\end{array}$ & NA & {$[12]$} \\
\hline 14 & 41 & L $3 \times 5$ & $\begin{array}{l}\text { Advanced } \\
\text { stage }\end{array}$ & 335.9 & 114.7 & $\begin{array}{l}\text { Sorafenib shifted to } \\
\text { combination of paclitaxel aNA } \\
\text { carboplatin }\end{array}$ & NA & [13] \\
\hline 15 & 62 & R $8.2 \times 7.8 \times 6.4$ & IA & 2450 & NA & $\begin{array}{l}\text { Bleomycin/vinblastine/cisplatin; } \\
\text { cisplatin/etoposide; } \\
\text { cyclophosphamide/mitomycin/ } \\
\text { 5-fluorouracil }\end{array}$ & Dead (I3 months) & [14] \\
\hline 16 & 52 & NA & III & 2500 & Elevated & $\begin{array}{l}\text { Carboplatin/ } \\
\text { cyclophosphamide/cisplatin }\end{array}$ & Recurred (7 months) & {$[15]$} \\
\hline 17 & 35 & $\mathrm{~L} 35 \times 30$ & IIIA & 358 & Normal & $\begin{array}{l}\text { Cyclophosphamide/cisplatin/ } \\
\text { carboplatin/etoposide; } \\
\text { paclitaxel }\end{array}$ & $\begin{array}{l}\text { Recurred/Dead (I8/22 } \\
\text { months) }\end{array}$ & {$[16]$} \\
\hline 18 & 53 & $\begin{array}{l}\operatorname{L9} \times 8 \times 6 ; R 8 \times \\
7 \times 6\end{array}$ & III & NA & 250 & Cisplatin/cyclophosphamide & Alive (12 months) & {$[17]$} \\
\hline 19 & 61 & $L 12 \times 9$ & III & 73,080 & 80 & $\begin{array}{l}\text { IP cisplatin; cisplatin/ } \\
\text { 5-fluorouracil/etoposide }\end{array}$ & Dead (20 months) & {$[18]$} \\
\hline 20 & 64 & R $23 \times 17 \times 16$ & IIIC & 900 & 53 & $\begin{array}{l}\text { Cisplatin/cyclophosphamide; } \\
\text { cisplatin/paclitaxel/radiation; } \\
\text { cisplatin/paclitaxel }\end{array}$ & $\begin{array}{l}\text { Recurred/Dead (18 } \\
\text { months/5 years) }\end{array}$ & [19] \\
\hline 21 & 36 & L $10 \times 8 \times 8$ & IIIC & NA & 888 & NA & NA & [20] \\
\hline 22 & 57 & $R 13 \times 9 \times 8$ & NA & 24,879 & NA & None & Alive (3 years) & {$[21]$} \\
\hline 23 & 63 & $R 16 \times 12$ & IA & 454 & 85 & Cisplatin/cyclophosphamide & Alive (7 months) & [22] \\
\hline
\end{tabular}


Table I (Continued).

\begin{tabular}{|c|c|c|c|c|c|c|c|c|}
\hline Case & Age & Site/Size $(\mathrm{cm})$ & Stage & AFP & CAI 25 & Post-Operative Treatment & Outcome & Reference \\
\hline 24 & 40 & $R I I \times 9.5 \times 3$ & III & 32,338 & 1297 & Chemotherapy & Alive (6 months) & {$[23]$} \\
\hline 25 & 50 & L $10 \times 8 ; R 7 \times 6$ & IIIC & 2 & 538 & $\begin{array}{l}\text { Cisplatin/paclitaxel; cisplatin/ } \\
\text { gemcitabine; doxorubicin }\end{array}$ & Dead (2 years) & [24] \\
\hline 26 & 65 & R $12 \times 10 \times 6$ & III & 329,732 & 402 & Cisplatin/paclitaxel & NA & {$[25]$} \\
\hline 27 & 42 & $\mathrm{~L} \mathrm{II} \times 7 \times 7$ & NA & NA & 70 & NA & NA & {$[26]$} \\
\hline 28 & 42 & $\mathrm{~L} 6 \times 4 \times 3$ & I & NA & NA & $\begin{array}{l}\text { Chemoradiation following } \\
\text { recurrence }\end{array}$ & NA & {$[27]$} \\
\hline 29 & 55 & $\mathrm{LII} \times 8 \times 7$ & IIIC & 249 & 168 & $\begin{array}{l}\text { Intraop IP nitrogen mustard; } \\
\text { docetaxel/nedaplatin }\end{array}$ & Alive (I0 months) & {$[28]$} \\
\hline 30 & 53 & $\begin{array}{l}L 7 \times 7 \times 6 ; R 9 \times \\
7 \times 6\end{array}$ & IIIC & 761 & 125 & Carboplatin/paclitaxel & Alive (I5 months) & [29] \\
\hline 31 & 57 & NA $12 \times 12 \times 12$ & IIIC & 397 & 1247 & $\begin{array}{l}\text { Intraop IP paclitaxel; } \\
\text { carboplatin/paclitaxel; } \\
\text { radiation (lumbar metastasis) }\end{array}$ & Alive (28 months) & {$[30]$} \\
\hline 32 & 73 & L $25 \times 17 \times 13$ & IIIC & $\begin{array}{c}2396 \\
\text { (postop) }\end{array}$ & NA & Carboplatin/paclitaxel & Alive (26 months) & {$[31]$} \\
\hline 33 & 78 & $\begin{array}{l}L 3.9 \times 4.1 ; R \\
6.8 \times 9.9\end{array}$ & NA & 150 & 100 & $\begin{array}{l}\text { Palliative chemotherapy } \\
\text { (distant metastasis) }\end{array}$ & Dead(I month) & [32] \\
\hline 34 & 47 & R $10 \times 10 \times 7$ & NA & 451.2 & 325.6 & Chemotherapy & Dead (3 months) & [33] \\
\hline 35 & 47 & $\begin{array}{l}\text { Multiple masses } \\
\text { coalescing to } \\
\text { a maximum } \\
\text { diameter of } 10\end{array}$ & NA & 6669 & 144 & CRS plus HIPEC(paclitaxel) & Alive (22 months) & [34] \\
\hline 36 & 27 & R 10 & IA & 1210 & 10.05 & Bleomycin/etoposide/platinum & Alive(36 months) & [35] \\
\hline 37 & 65 & L 13 & IC & $83,164.6$ & 340.8 & Carboplatin/paclitaxel & Dead(3I months) & [36] \\
\hline 38 & 66 & $\begin{array}{l}\text { L I5×10, } 8 \times 7 \\
\text { omental bursa } \\
5 \times 4\end{array}$ & IIIC & $\begin{array}{c}2.05 \\
\text { (normal) }\end{array}$ & 795.4 & Carboplatin/docetaxel & Dead (3 months) & $\begin{array}{l}\text { Present } \\
\text { case I }\end{array}$ \\
\hline 39 & 48 & R $8 \times 8 \times 6$ & IC2 & $>24,200$ & 81.95 & Paclitaxel liposome/carboplatin & Alive (22 months) & $\begin{array}{c}\text { Present } \\
\text { case } 2\end{array}$ \\
\hline
\end{tabular}

Notes: Part of the table is cited from Randolph LK's report. ${ }^{31}$ (OA, CC BY-NC-ND).

were partially cystic with abundant blood flow signals by ultrasound examination. Microscopically, primary $\mathrm{HCO}$ behaves like HCC, with tumor cells arranged in sheets, cords, or trabeculae, sometimes with glandular and papillary structures. Cells usually have an eosinophilic cytoplasm with large and irregular nuclei that show high mitotic activity. Both of our patients showed typical pathologic manifestations. AFP is the most commonly used biochemical marker for $\mathrm{HCO}$ and is negative in rare cases. Despite negative immunostaining for AFP, these carcinomas with typical histologic features of a $\mathrm{HC}$ have been classified as $\mathrm{HC}^{1}$ as was undifferentiated carcinoma with abundant eosinophilic cytoplasm and immunonegativity for $\mathrm{AFP}^{2}$ In our patient who was negative for AFP by immunohistochemistry, the tumor consisted of solid sheets of cells with abundant eosinophilic cytoplasm, distinct cell borders, and centrally located nuclei with prominent nucleoli, which is a typical histologic feature of HC. 
Table 2 Clinical Features, Treatment, and Outcomes of HCU

\begin{tabular}{|c|c|c|c|c|c|c|c|c|}
\hline Age & Site/Size & m) & Stage & AFP & CAI 25 & Post-Operative & Outcome & Reference \\
\hline 86 & Body & $10.5 \times 6 \times 3.7$ & NA & 7824 & 14.3 & $\begin{array}{l}\text { Chemotherapy (VP-16), } \\
\text { radiation }\end{array}$ & $\begin{array}{l}\text { Recurred after } \\
\text { surgery II months, } \\
\text { alive }>36 \text { months }\end{array}$ & [8] \\
\hline 61 & Body & NA & NA & 453 & 99.2 & $\begin{array}{l}\text { Chemotherapy } \\
\text { (carboplatin/paclitaxel) }\end{array}$ & NED, 12 months & [37] \\
\hline 65 & $C x$ & $3.0 \times 2.5 \times 2.0$ & $|B|$ & 105 & NA & Radiation & Recurred, 12 months & [38] \\
\hline 63 & Body & 5 & NA & 5060 & NA & $\begin{array}{l}\text { Chemotherapy } \\
\text { (carboplatin/paclitaxel) }\end{array}$ & Dead, 12 months & [39] \\
\hline 68 & Body $\sim C x$ & $3.5 \times 3.5 \times 1.5$ & NA & 2800 & NA & NA & NA & [40] \\
\hline 66 & Body & 6 & IIIA & $\begin{array}{l}35 \text { I (4 days } \\
\text { after } \\
\text { operation) }\end{array}$ & NA & $\begin{array}{l}\text { Chemotherapy } \\
\text { (carboplatin/ } \\
\text { cyclophosphamide/ } \\
\text { doxorubicin) }\end{array}$ & NED, 8 months & {$[4 \mid]$} \\
\hline 60 & Body & $6 \times 5 \times 4$ & NA & 31,950 & Normal & $\begin{array}{l}\text { Chemotherapy } \\
\text { (carboplatin/ } \\
\text { cyclophosphamide/ } \\
\text { doxorubicin) }\end{array}$ & Dead, 12 months & {$[42]$} \\
\hline 66 & Body $\sim C x$ & NA & NA & 16,170 & NA & Radiation & Dead, 32 months & {$[43]$} \\
\hline 62 & Body $\sim C x$ & NA & NA & 280 & NA & $\begin{array}{l}\text { Chemotherapy } \\
\text { (carboplatin/ } \\
\text { cyclophosphamide/ } \\
\text { doxorubicin) }\end{array}$ & Dead, 4 months & {$[44]$} \\
\hline 61 & Body & $3.0 \times 1.5 \times 0.9$ & $\begin{array}{l}\text { Advanced } \\
\text { stage }\end{array}$ & 253.3 & Normal & $\begin{array}{l}\text { Radiation;Chemotherapy } \\
\text { (paclitaxel, carboplatin) }\end{array}$ & Dead, I 6months & {$[45]$} \\
\hline 48 & Body & $4.0 \times 3.0$ & IA & 1210 & Normal & $\begin{array}{l}\text { Chemotherapy (taxol, } \\
\text { carboplatin) }\end{array}$ & Alive 63 months & $\begin{array}{l}\text { Present } \\
\text { case } 3\end{array}$ \\
\hline
\end{tabular}

Note: Part of the table is cited from Ishibashi K's report ${ }^{8}$ (OA, CC BY-NC-ND).

Abbreviations: $\mathrm{HCC}$, hepatocellular carcinoma; $\mathrm{HCO}$, hepatoid carcinoma of the ovary; $\mathrm{HCU}$, hepatoid carcinoma of uterus; $\mathrm{CT}$, computed tomography; MR, Magnetic Resonance; CA, cancer antigen; AFP, $\alpha$-fetoprotein; CD, cluster of differentiation;CK, cytokeratin; DWI, diffusion-weighted imaging; GPC3, glypican 3; HBsAg, hepatitis B surface antigen; HNF-4 $\alpha$, hepatocyte nuclear factor 4 alpha; OCT4, octamer-binding protein 4; SALL4, Sal-like protein 4; CYFRA2I-I, cytokeratin-19-fragment; AMH, antimullerian hormone; PSTT, placental site trophoblastic tumor; HYST, hepatoid yolk sac tumor; L, left; R, right; NA, not available; NED, no evidence of disease.

AFP production is closely coupled to cell division and the degree of cell differentiation; neoplastic cells only transiently produce AFP, leading to negative AFP staining. Thus, AFP immunopositivity is not essential for diagnosing AFP-secreting tumors such as $\mathrm{HCO}{ }^{2}$

HYST is another ovarian tumor characterized by hepatoid differentiation and AFP production that should be distinguished from $\mathrm{HCO}$, which is relatively straightforward. $^{12}$ HCO can be distinguished from HCC based on detection of hepatocyte paraffin 1 and the presence of bile, microscopic findings, and immunonegativity for CA125. ${ }^{46}$ In addition to hepatocyte paraffin $1, \mathrm{HCC}$ is positive for SALL4, a frequently used marker of germ cell tumors. ${ }^{47}$ We consider that diffuse positivity for SALL4 is suggestive of HYST rather than $\mathrm{HCO}$, especially in women of childbearing age. However, immunopositivity for SALL4 has been reported in HCO cases. Our case 2 was negative for SALL4. The presence of a surface epithelial carcinoma component strongly favors a diagnosis of HC over HYST. ${ }^{11}$ One study suggested that immunohistochemical detection of hepatocyte nuclear factor (HNF)- $4 \alpha$ may be helpful in distinguishing between hepatoid 
adenocarcinoma and the solid component of high-grade endometrioid adenocarcinomas, because all examined cases of endometrioid adenocarcinoma were negative for HNF- $4 \alpha$; these authors speculated that liver-enriched nuclear factors such as HNF-4 $\alpha$ may be involved in hepatic differentiation of the tumor, ${ }^{8}$ although the underlying molecular mechanism is unclear.

According to our review, survival time in patients with $\mathrm{HCO}$ ranged from 1 month to 5 years (2- and 5-year survival rates $<50 \%$ and $<10 \%$, respectively). The prognosis of patients with $\mathrm{HCU}$ is equally poor, with only one patient (our case 3 ) surviving $>5$ years. The optimal treatment for $\mathrm{HCO}$ remains to be determined. Most cases are treated as ovarian-like cancer-ie, with surgery plus chemotherapy (carboplatin plus paclitaxel). The tyrosine kinase inhibitor sorafenib has been used as a second-line treatment but its efficacy is undetermined; in one study, second-line sorafenib was discontinued because AFP level increased and the disease progressed, ${ }^{12}$ and in another study the patient's condition deteriorated after 2 months of treatment and the chemotherapy regimen was switched to carboplatin plus paclitaxel. ${ }^{13}$ However, one case treated with sorafenib achieved a progression-free survival of 7 months. ${ }^{48}$ All of our patients underwent cytoreductive surgery for their tumor and received postoperative chemotherapy with carboplatin/docetaxel and carboplatin/paclitaxel liposome. The patient with HCU who was treated with carboplatin plus paclitaxel liposome responded well to this regimen and achieved a progression-free survival >56 months. Hysterectomy and bilateral adnexectomy were performed in all cases of HCU reported to date and most patients received adjuvant chemotherapy while some were treated with radiotherapy. Two of our patients were treated with 6 cycles of chemotherapy and did not receive radiotherapy; our case 3 was diagnosed with stage IA HCU and achieved a good clinical outcome after treatment.

\section{Conclusion}

Based on our 3 cases and review of the literature, we conclude that first-line treatment for both HCO and HCU should be staging surgery followed by platinum-based chemotherapy.

\section{Ethics Statement}

All patients (or next of kin for the deceased patient) provided written informed consent for the case details and images to be published. This research was conducted according to the guidelines put forth in the Declaration of Helsinki. Institutional approval to publish the case details is exempt.

\section{Disclosure}

The authors report no conflicts of interest in this work.

\section{References}

1. Ishikura H, Scully RE. Hepatoid carcinoma of the ovary - a newly described tumor. Cancer. 1987;60(11):2775-2784. doi:10.1002/10970142(19871201)60:11<2775::AID-CNCR2820601130>3.0.CO;2-S

2. Nishida T, Sugiyama T, Kataoka A, et al. Ovarian hepatoid carcinoma without staining for alpha-fetoprotein in the primary site. Int $J$ Gynecol Cancer. 1995;5(4):314-318. doi:10.1046/j.15251438.1995.05040314.x

3. Young RH, Gersell DJ, Clement PB, Scully RE. Hepatocellularcarcinoma metastatic to the ovary - a report of 3 cases discovered during life with discussion of the differential-diagnosis of hepatoid tumors of the ovary. Hum Pathol. 1992;23(5):574-580. doi:10.1016/ 0046-8177(92)90136-Q

4. Su J-S, Chen Y-T, Wang R-C, Wu C-Y, Lee S-W, Lee T-Y. Clinicopathological characteristics in the differential diagnosis of hepatoid adenocarcinoma: a literature review. World J Gastroenterol. 2013;19(3):321-327. doi:10.3748/wjg.v19.i3.321

5. Lazaro J, Rubio D, Repolles M, Capote L. Hepatoid carcinoma of the ovary and management. Acta Obstet Gynecol Scand. 2007;86 (4):498-499. doi:10.1080/00016340600593117

6. Prat J, D'Angelo E, Espinosa I. Ovarian carcinomas: at least five different diseases with distinct histological features and molecular genetics. Hum Pathol. 2018;80:11-27. doi:10.1016/j. humpath.2018.06.018

7. Prat J. Ovarian carcinomas: five distinct diseases with different origins, genetic alterations, and clinicopathological features. Virchows Arch. 2012;460(3):237-249. doi:10.1007/s00428-012-1203-5

8. Ishibashi K, Kishimoto T, Yonemori Y, Hirashiki K, Hiroshima K, Nakatani Y. Primary hepatoid adenocarcinoma of the uterine corpus: a case report with immunohistochemical study for expression of liver-enriched nuclear factors. Pathol Res Pract. 2011;207 (5):332-336. doi:10.1016/j.prp.2011.02.010

9. Matsuta M, Ishikura H, Murakami K, Kagabu T, Nishiya I. Hepatoid carcinoma of the ovary - a case-report. Int J Gynecol Pathol. 1991;10 (3):302-310. doi:10.1097/00004347-199107000-00009

10. Scurry JP, Brown RW, Jobling T. Combined ovarian serous papillary and hepatoid carcinoma. Gynecol Oncol. 1996;63(1):138-142. doi:10.1006/gyno.1996.0293

11. Tochigi N, Kishimoto T, Supriatna Y, Nagai Y, Nikaido T, Ishikura H. Hepatoid carcinoma of the ovary: a report of three cases admixed with a common surface epithelial carcinoma. Int J Gynecol Pathol. 2003;22(3):266-271. doi:10.1097/01.PGP.0000055173.04957.66

12. Pandey M, Truica C. Hepatoid carcinoma of the ovary. J Clin Oncol. 2011;29(15):E446-E8. doi:10.1200/JCO.2010.33.6321

13. Mahmood H, Fatima H, Faheem M. Metastatic hepatoid carcinoma of ovarian origin - A case report from Northern Pakistan. Gynecol Oncol Rep. 2017;21:24. doi:10.1016/j.gore.2017.05.007

14. Tamakoshi K, Horio J, Okamoto T, Sakakibara K, Hattori S. A case report of hepatoid carcinoma of the ovary. Nihon Sanka Fujinka Gakkai Zasshi. 1993;45(5):479-481.

15. Badreddine J, Rabouille Y, Heron JF, Mandard AM. Ovarian tumor with hepatoid differentiation - report of one case and review of the literature. Ann Pathol. 1993;13(1):37-39.

16. Maymon E, Piura B, Mazor M, Bashiri A, Silberstein T, Yanai-Inbar I. Primary hepatoid carcinoma of ovary in pregnancy. Am J Obstet Gynecol. 1998;179(3):820-822. doi:10.1016/S0002-9378(98)70092-4 
17. Trivedi P, Dave K, Shah M, Karelia N, Patel D, Wadhwa M. Hepatoid carcinoma of the ovary - a case report. Eur J Gynaecol Oncol. 1998;19(2):167-169.

18. Senzaki H, Kiyozuka Y, Mizuoka H, et al. An autopsy case of hepatoid carcinoma of the ovary with PIVKA-II production: immunohistochemical study and literature review. Pathol Int. 1999;49 (2):164-169. doi:10.1046/j.1440-1827.1999.00840.x

19. Lee CH, Huang KG, Ueng SH, Swei H, Chueh KY, Lao CH. A hepatoid carcinoma of the ovary. Acta Obstet Gynecol Scand. 2002;81(11):1080-1082. doi:10.1034/j.1600-0412.2002.811115.x

20. Watanabe Y, Umemoto M, Ueda H, Nakai H, Hoshiai H, Noda K. Cytopathologic and clinicopathologic features of ovarian hepatoid carcinoma - a case report. Acta Cytol. 2003;47(1):78-82. doi:10.1159/000326479

21. Tsung JS, Yang PS. Hepatoid carcinoma of the ovary: characteristics of its immunoreactivity. a case report. Eur $J$ Gynaecol Oncol. 2004;25(6):745-748.

22. Yigit S, Uyaroglu MA, Kus Z, Ekinci N, Oztekin O. Hepatoid carcinoma of the ovary: immunohistochemical finding of one case and literature review. Int J Gynecol Cancer. 2006;16(3):1439-1441. doi:10.1136/ijgc-00009577-200605000-00075

23. Kwon JE, Kim SH, Cho NH. No ancillary finding is valid to distinguish a primary ovarian hepatoid carcinoma from metastatic hepatocellular carcinoma. Int J Gynecol Cancer. 2006;16(4):1691-U5. doi:10.1111/j.1525-1438.2006.00646.x

24. Ozan H, Nazhoglu HO, Ozuysal S. A case of hepatoid carcinoma of the ovary. Eur J Gynaecol Oncol. 2008;29(5):556-557.

25. Gonzalez ET, Arguelles M, Jimenez-Heffernan JA, Dhimes P, Vicandi B, Pinedo F. Cytologic features of hepatoid carcinoma of the ovary: a case report with immunocytologic evaluation of HepPar1. Acta Cytol. 2008;52(4):490-494. doi:10.1159/000325560

26. Zizi-Sermpetzoglou A, Petrakopoulou N, Nikolaidou ME, Tepelenis N, Savvaidou V, Vasilakaki T. Hepatoid carcinoma of the ovary. A case report and review of the literature. Eur J Gynaecol Oncol. 2009;30(3):341-343.

27. D’Antonio A, De Dominicis G, Addesso M, Caleo A, Boscaino A. Hepatoid carcinoma of the ovary with sex cord stromal tumor: a previously unrecognized association. Arch Gynecol Obstet. 2010;281(4):765-768. doi:10.1007/s00404-009-1259-x

28. Liu XL, Wang X, Zhu FF. Hepatoid carcinoma of the ovary: a case report and review of the literature. Oncol Lett. 2012;4(5):947-950. doi:10.3892/ol.2012.879

29. Cascales Campos PA, Gil Martinez J, Torroba A, Machado F, Parrila Paricio P. Peritoneal dissemination of hepatoid carcinoma of the ovary treated with cytoreductive surgery and hyperthermic intraoperative intraperitoneal chemotherapy. Case Rep Med. 2013;2013:283295. doi:10.1155/2013/283295

30. Wang L, Zhong Y, Sun L, Zhou H, Chen W, Zhang X. Clinical and pathological features of hepatoid carcinoma of the ovary. World J Surg Oncol. 2013;11:1-5. doi:10.1186/1477-7819-11-1

31. Randolph LK, Hopkins MK, Hopkins MP, Wasdahl DA. Hepatoid carcinoma of the ovary: a case report and review of the literature. Gynecol Oncol Rep. 2015;13:64-67. doi:10.1016/j.gore.2015.06.006

32. Mazouz A, Amaadour L, Ameurtesse H, et al. Primary hepatoid carcinoma of the ovary: a case report. Pan Afr Med J. 2015;20.

33. Lakhotia M, Pahadiya HR, Choudhary A, Gandhi R, Purohit RC. A rare case of hepatoid carcinoma of the ovary with pancytopenia and hypocellular marrow. Indian J Med Paediatr Oncol. 2016;37 (4):307. doi:10.4103/0971-5851.195744
34. Naffouje SA, Anderson RR, Salti GI. A case report of Hepatoid Carcinoma of the Ovary with peritoneal metastases treated with cytoreductive surgery and hyperthermic intraoperative intraperitoneal chemotherapy without systemic adjuvant therapy. Int J Surg Case Rep. 2016;27:83-86. doi:10.1016/j.ijscr.2016.08.020

35. Uribe Rivera AK, Alvarez Larraondo M, Taxa Rojas L, Bravo Taxa M, Zevallos Cardenas A. Hepatoid carcinoma of the ovary a case report and literature review. Gynecol Oncol Rep. 2020;32:100564. doi:10.1016/j.gore.2020.100564

36. Choi WK, Cho DH, Yim CY, Lee NR. Primary hepatoid carcinoma of the ovary: a case report and review of the literature. Medicine (Baltimore). 2020;99(19):e20051. doi:10.1097/ MD.0000000000020051

37. Takeuchi K, Kitazawa S, Hamanishi S, Inagaki M, Murata K. A case of alpha-fetoprotein-producing adenocarcinoma of the endometrium with a hepatoid component as a potential source for alpha-fetoprotein in a postmenopausal woman. Int $J$ Gynecol Cancer. 2006;16 (3):1442-U6. doi:10.1111/j.1525-1438.2006.00613.x

38. Kato K, Suzuka K, Osaki T, Itami M, Tanaka N. Primary hepatoid adenocarcinoma of the uterine cervix. Int J Gynecol Cancer. 2007;17 (5):1150-1154. doi:10.1111/j.1525-1438.2007.00901.x

39. Takano M, Shibasaki T, Sato K, Aida S, Kikuchi Y. Malignant mixed Mullerian tumor of the uterine corpus with alpha-fetoproteinproducing hepatoid adenocarcinoma component. Gynecol Oncol. 2003;91(2):444-448. doi:10.1016/S0090-8258(03)00512-2

40. Takahashi Y, Inoue T. Hepatoid carcinoma of the uterus that collided with carcinosarcoma. Pathol Int. 2003;53(5):323-326. doi:10.1046/ j.1440-1827.2003.01467.x

41. Adams SF, Yamada SD, Montag A, Rotmensch JR. An alpha-fetoprotein-producing hepatoid adenocarcinoma of the endometrium. Gynecol Oncol. 2001;83(2):418-421. doi:10.1006/ gyno.2001.6383

42. Toyoda H, Hirai T, Ishii E. Alpha-fetoprotein producing uterine corpus carcinoma: a hepatoid adenocarcinoma of the endometrium. Pathol Int. 2000;50(10):847-852. doi:10.1046/j.1440-1827.2000.01124.x

43. Hoshida Y, Nagakawa T, Mano S, Taguchi K, Aozasa K. Hepatoid adenocarcinoma of the endometrium associated with alpha-fetoprotein production. Int $J$ Gynecol Pathol. 1996;15 (3):266-269. doi:10.1097/00004347-199607000-00012

44. Yamamoto R, Ishikura H, Azuma M, et al. Alpha-fetoprotein production by a hepatoid adenocarcinoma of the uterus. J Clin Pathol. 1996;49(5):420-422. doi:10.1136/jcp.49.5.420

45. Wu QY, Wan XY, Xie X, Lu BJ. Endometrial hepatoid adenocarcinoma: a rare cause of elevated serum a- fetoprotein. J Obstet Gynaecol Res. 2014;40(3):873-877. doi:10.1111/jog.12237

46. Pitman MB, Triratanachat S, Young RH, Oliva E. Hepatocyte paraffin 1 antibody does not distinguish primary ovarian tumors with hepatoid differentiation from metastatic hepatocellular carcinoma. Int J Gynecol Pathol. 2004;23(1):58-64. doi:10.1097/01. pgp.0000101141.31270.a1

47. Ushiku T, Shinozaki A, Shibahara J, et al. SALL4 represents fetal gut differentiation of gastric cancer, and is diagnostically useful in distinguishing hepatoid gastric carcinoma from hepatocellular carcinoma. Am J Surg Pathol. 2010;34(4):533-540. doi:10.1097/ PAS.0b013e3181d1dcdd

48. Petrelli F, Ghilardi M, Colombo S, et al. A rare case of metastatic pancreatic hepatoid carcinoma treated with sorafenib. J Gastrointest Cancer. 2012;43(1):97-102. doi:10.1007/s12029-011-9264-2 


\section{Publish your work in this journal}

Cancer Management and Research is an international, peer-reviewed open access journal focusing on cancer research and the optimal use of preventative and integrated treatment interventions to achieve improved outcomes, enhanced survival and quality of life for the cancer patient.
The manuscript management system is completely online and includes a very quick and fair peer-review system, which is all easy to use. Visit http://www.dovepress.com/testimonials.php to read real quotes from published authors. 